\title{
BMJ Open Evaluating the effectiveness of a peer- led education intervention to improve the patient safety attitudes of junior pharmacy students: a cross-sectional study using a latent growth curve modelling approach
}

\author{
Ramesh L Walpola, ${ }^{1}$ Romano A Fois, ${ }^{1}$ Andrew J McLachlan, ${ }^{1,2}$ Timothy F Chen ${ }^{1}$
}

To cite: Walpola RL, Fois RA, McLachlan AJ, et al. Evaluating the effectiveness of a peer-led education intervention to improve the patient safety attitudes of junior pharmacy students: a cross-sectional study using a latent growth curve modelling approach. BMJ Open 2015;5:e010045. doi:10.1136/bmjopen-2015010045

- Prepublication history for this paper is available online. To view these files please visit the journal online (http://dx.doi.org/10.1136/ bmjopen-2015-010045).

Received 19 September 2015 Revised 20 October 2015 Accepted 27 October 2015

CrossMark

\begin{abstract}
${ }^{1}$ Faculty of Pharmacy, The University of Sydney, Camperdown, New South Wales, Australia

${ }^{2}$ Centre for Education and Research on Ageing, Concord Repatriation General Hospital, Concord, Sydney, New South Wales, Australia
\end{abstract}

\section{Correspondence to}

Ramesh L Walpola; ramesh.walpola@sydney.edu. $\mathrm{au}$

\section{ABSTRACT}

Objective: Despite the recognition that educating healthcare students in patient safety is essential, changing already full curricula can be challenging. Furthermore, institutions may lack the capacity and capability to deliver patient safety education, particularly from the start of professional practice studies. Using senior students as peer educators to deliver practice-based education can potentially overcome some of the contextual barriers in training junior students. Therefore, this study aimed to evaluate the effectiveness of a peer-led patient safety education programme for junior pharmacy students.

Design: A repeat cross-sectional design utilising a previously validated patient safety attitudinal survey was used to evaluate attitudes prior to, immediately after and 1 month after the delivery of a patient safety education programme. Latent growth curve (LGC) modelling was used to evaluate the change in attitudes of first-year students using second-year students as a comparator group.

Setting: Undergraduate university students in Sydney, Australia.

Participants: 175 first-year and 140 second-year students enrolled in the Bachelor of Pharmacy programme at the University of Sydney.

Intervention: An introductory patient safety programme was implemented into the first-year Bachelor of Pharmacy curriculum at the University of Sydney. The programme covered introductory patient safety topics including teamwork, communication skills, systems thinking and open disclosure. The programme consisted of 2 lectures, delivered by a senior academic, and a workshop delivered by trained final-year pharmacy students.

Results: A full LGC model was constructed including the intervention as a non-time-dependent predictor of change $\left(\chi^{2}(51)=164.070\right.$, root mean square error of approximation $=0.084$, comparative fit index $=0.913$, standardised root mean square $=0.056$ ). First-year students' attitudes significantly improved as a result of the intervention, particularly in relation to internalising

\section{Strengths and limitations of this study}

- This is the first study to evaluate the use of senior healthcare students to train junior healthcare students in patient safety principles.

- The effectiveness of a peer-led education intervention for junior pharmacy students was evaluated using a previously validated survey tool to measure patient safety attitudes.

- Latent growth curve analysis, a robust statistical method that enables both interindividual and intraindividual evaluation, was used to evaluate the differences in attitudinal changes between an intervention and comparator group.

- The results highlight that senior students can have an influential role in improving junior students' clinical practice attitudes and enhancing professional socialisation, which has implications for the development of all healthcare students curriculum.

errors $(p=0.010)$, questioning behaviours $(p<0.001)$ and open disclosure $(p=0.008)$.

Conclusions: Peer-led education is an effective method that can be adopted to improve junior pharmacy students' attitudes towards patient safety.

\section{INTRODUCTION}

Since patient safety was acknowledged as a global healthcare priority, numerous strategies have been developed to improve safety. Education is one strategy that has been considered as one of the key elements necessary in order to improve the patient safety attitudes and practices of healthcare professionals. ${ }^{1}{ }^{2}$ As a key stakeholder in patient safety, the WHO has supported the 
implementation of patient safety education through the development of the Patient Safety Curriculum Guide, ${ }^{3}$ which has been designed to assist curriculum development for all healthcare disciplines, including pharmacy. Despite education being considered a relatively simple solution, changing already full curricula can be challenging, compounded by limited resources and educators experienced in delivering patient safety-related education. ${ }^{4}$

Prior to entering professional practice, there are a number of patient safety skills that healthcare students should have developed including: the ability to recognise and manage working in unsafe conditions; be able to take a systems approach to the provision of healthcare; and to be able to manage errors and their causal factors; as well as be able to openly disclose errors. ${ }^{5}{ }^{6}$ It has been shown that medical students that are trained in patient safety skills prior to entering their clinical training have the potential to prevent harm and save lives. ${ }^{7}$ While many medical and nursing schools have embraced this and implemented junior curriculum changes, this has not been necessarily the case with many allied health curricula globally. Currently as part of many undergraduate pharmacy degree programmes, much of the patient safety training is delivered in the final years of the degrees. This, however, may be counterproductive to the students' professional development, as by this stage many pharmacy students have gained a significant amount of work experience either through experiential learning placements or through casual employment. As much of the patient safety training is focused on behavioural and practice issues, it is likely that suboptimal practices have already been developed by this stage. 89

In recognition of the importance of a good foundation in patient safety, it was planned that patient safety training for pharmacy students enrolled in the Bachelor of Pharmacy programme at the University of Sydney would be restructured with patient safety principles introduced from their first year of study. However, delivering effective practice-based education to a group of students at the infancy of their professional career also has challenges as a result of having students who are recent high school leavers with limited clinical experience. ${ }^{10}$ Studies demonstrate that positive role models, encouragement and non-didactic learning methods are engaging and effective in improving knowledge and attitudes of students towards patient safety. ${ }^{11}{ }^{12}$ Hence, peer-led education was identified as a potential solution and has already been shown to build capacity and capability in delivering patient safety education. ${ }^{13}{ }^{14}$ By using senior students as educators and positive role models, it was thought that junior students would have the ability to relate to the subject matter in a less intimidating environment. ${ }^{15}$ Therefore, the aim of this study was to evaluate the effectiveness of a peer-led patient safety education programme for junior pharmacy students, with the specific objectives of examining the effectiveness of the programme in changing their attitudes towards preclinical patient safety core skill areas: undertaking quality improvement activities, discussing errors, questioning unsafe behaviours and the open disclosure of errors.

\section{METHODS}

A pre-post intervention study design was used, with firstyear pharmacy students being surveyed on their patient safety attitudes prior to, immediately after and 1 month post-intervention. Second-year pharmacy students who did not receive the intervention were also surveyed at identical time points to act as a comparator group. Data were collected between May and October 2013.

\section{Recruitment}

The study sample was drawn from all 508 pharmacy students enrolled in the first $(n=249)$ and second $(n=259)$ years of the Bachelor of Pharmacy programme at the University of Sydney, Australia.

Peer leaders were recruited from final-year (fourth year) students $(n=36)$ enrolled in the Bachelor of Pharmacy programme. Peer leaders were required to attend a training session which consisted of leadership skills as well as the specific patient safety concepts required to teach the workshop, to supplement comprehensive patient safety education received in their third year of the Bachelor of Pharmacy programme.

\section{Intervention}

An introductory patient safety programme was developed for implementation in the first-year Bachelor of Pharmacy curriculum. The programme was designed to integrate into a second semester clinical practice-based unit of study, which focuses on psychosocial elements of healthcare delivery. Specifically, the programme introduced students to a number of the WHO Patient Safety Curriculum topics including 'defining patient safety', 'introduction to human factors', 'understanding systems', 'being an effective team player', 'learning from errors', 'understanding and managing clinical risk', 'engaging with patients and carers' and 'improving medication safety'. The programme consisted of two components: two $1 \mathrm{~h}$ lectures followed by a $2 \mathrm{~h}$ workshop. The lectures were delivered by an expert academic in patient safety and introduced students to the basic concepts of patient safety through a series of case studies based on actual patient experiences. The lecture material was then reinforced through a $2 \mathrm{~h}$ workshop that was led by four trained final-year volunteer peer leaders. The workshop began with a scenario, role played by the peer leaders that highlighted a number of events that resulted in a patient being harmed while receiving healthcare. Peer leaders then split the first-year classes into small groups of four to eight first-year students in which, as a peer group, they would deconstruct the incidents through a series of games and exercises. The first-year students were also trained in 
communication techniques based on the Team Strategies and Tools To Enhance Performance and Patient Safety (TeamSTEPPS) framework $^{16}$ and role played scenarios with the peer leaders to practice the techniques. Through the intervention, first-year students were trained in identifying, understanding, reporting and managing risk with a focus placed on developing better communication skills and graded assertiveness when working within a team.

\section{Evaluation}

Survey

First-year and second-year pharmacy students' patient safety attitudes were evaluated using a previously validated 23-item survey based on the Patient Safety/Medical Fallibility Curriculum Survey developed by Madigosky et $a l^{5}{ }^{17}$ The survey consisted of two sections. The first section contained 17 of the 18 attitudinal items of the original Patient Safety/Medical Fallibility Curriculum Survey, ${ }^{5}$ with items related to the reporting of errors split into two items to evaluate attitudinal differences in the presence or absence of patient harm. An additional four items were also included in the survey: an attitudinal item related to peer learning; two items related to questioning more senior healthcare professionals; and one item on patients' role in their healthcare. The second section collected demographic details including gender, age, stage of education, prior healthcare experience and involvement with an incident that resulted in harm or potential harm as a result of receiving healthcare. The survey utilised a five-point Likert-type scale to measure student attitudes, with possible responses ranging from strongly disagree to strongly agree.

\section{Statistical analysis}

All analyses were completed using IBM SPSS Statistics V.21 (SPSS Inc, Chicago, Illinois, USA) and AMOS V.21 (Amos Development Corporation, Meadville, Pennsylvania, USA). From the previous validation study of the survey tool, confirmatory factor analysis identified four attitudinal domains which could be measured by the survey: willingness to undertake quality improvement activities (QI), likelihood to internalise errors (IE), willingness to question other healthcare professional's behaviours $(\mathrm{QB})$ and willingness to the open disclosure of errors to patients (OD). ${ }^{17}$ Based on the validated factor structure, factor-based weighted sum scores for each of the attitudinal domains were calculated. ${ }^{18}$ List wise deletion of cases with missing data was performed to ensure a complete data set for analysis due to student attrition.

Latent growth curve (LGC) modelling was used to analyse the changes in attitudinal scores over time. This method allowed for the analysis of both intraindividual and interindividual changes over time by creating a regression curve based on each student's responses to the survey. ${ }^{19}$

A single latent growth model was created using all four attitudinal constructs within one model. Two latent factors per attitudinal construct were estimated: the intercept, which represents the baseline attitudinal score, and the slope, which represents the changes over time. The intercept parameters were constrained to 1 for each attitudinal score to represent baseline scores; however, the values of 0,2 and 3 , respectively, were assigned to the slope parameters to indicate the elapsed time in between each of the three survey time points. The year group in which students were enrolled was included to the model as a time invariant predictor of change to enable the evaluation of the effectiveness of the programme between the intervention group (year 1) and comparator group (year 2). All factor error terms were allowed to co-vary due to the inter-relationships between the original survey items, with non-significant covariance paths removed. The model was evaluated using maximum likelihood estimation with model goodness of fit evaluated by $\chi^{2}$, root mean square error of approximation (RMSEA), comparative fit index (CFI) and standardised root mean square (SRMR). ${ }^{19}$

\section{RESULTS}

\section{Participant characteristics}

A total of 175 first-year and 140 second-year students completed the survey at all three time points, resulting in survey response rates of $70.6 \%$ and $54.1 \%$, respectively. As shown in table 1 , the demographic characteristics of first-year and second-year students were not significantly different, with the exception of the number of students who were currently employed part-time in pharmacy and the time period they have been working in pharmacy. However, this was not expected to impact the results as the students had been employed for a relatively short period of time on average (2.4 vs 6.2 months), and did not engage primarily in clinical roles (3\% vs 13\%). Comparisons between demographic characteristics and survey item responses showed that none of the measured demographic characteristics were associated with any of the responses to the survey items. ${ }^{17}$

\section{Effectiveness of the intervention}

Figure 1 shows the full LGC model constructed with reasonable model fit obtained, $\chi^{2} \quad(51)=164.070$, RMSEA $=0.084$, CFI $=0.913$, SRMR $=0.056$. The effect of the intervention on attitudinal scores (table 2) highlights a significant improvement in the intervention group's (year 1) attitudinal scores in: being less likely to internalise errors $(p=0.010)$; more likely to question another healthcare professional's behaviours $(p<0.001)$; and being more likely to openly disclose an error to a patient $(\mathrm{p}=0.008)$.

From the LGC model, it can be observed that at baseline (represented by ICEPT in figure 1) all four attitudinal domains are correlated (covariance $\geq 0.30$ ). However, correlations that affect changes to the scores that measure these attitudinal domains (represented by SLOPE in figure 1) are quite different. The model 
Table 1 Participant characteristics

\begin{tabular}{|c|c|c|c|}
\hline Characteristic & $\begin{array}{l}\text { First-year } \\
\text { students } \\
(n=175)\end{array}$ & $\begin{array}{l}\text { Second-year } \\
\text { students } \\
(n=140)\end{array}$ & p Value \\
\hline \multicolumn{4}{|l|}{ Gender } \\
\hline Males, $\mathrm{n}(\%)^{\star}$ & $60(34.3)$ & $39(27.9)$ & 0.368 \\
\hline Females, $\mathrm{n}(\%)^{\star}$ & $115(65.7)$ & $101(72.1)$ & \\
\hline Age, in years, mean (SD) & $19.4(4.0)$ & $20.0(2.2)$ & 0.097 \\
\hline $\begin{array}{l}\text { Healthcare work or study experience prior to start of Bachelor of } \\
\text { Pharmacy programme, } n(\%)^{*}\end{array}$ & $22(13.0)$ & $29(20.7)$ & 0.750 \\
\hline Students currently working in a pharmacy prior to the intervention, $\mathrm{n}(\%)^{*}$ & $26(14.9)$ & $58(41.4)$ & $<0.001$ \\
\hline Months worked in pharmacy prior to the intervention (mean, SD) & $2.2(8.5)$ & $4.8(8.0)$ & 0.006 \\
\hline Students currently working in a pharmacy after the intervention, $\mathrm{n}(\%)^{*}$ & $34(19.4)$ & $66(47.5)$ & $<0.001$ \\
\hline Months worked in pharmacy after the intervention (mean, SD) & $2.4(7.3)$ & $6.2(10.2)$ & $<0.001$ \\
\hline
\end{tabular}

illustrates that the intervention has a significant impact on changing three of the four attitudinal domains: IE, $\mathrm{QB}$ and OD. Of these three domains, QB and OD are affected by changes to each other, in addition to students' attitudinal changes towards undertaking QI. The model also illustrates that the intervention alone led to significant improvement on IE attitudinal scores. The only attitudinal domain that was not directly affected by the intervention was students' attitudes to QI. Although students' attitudes to this domain did not change significantly as a result of the intervention, strong correlations between changes to $\mathrm{QI}$ are related to changes in $\mathrm{QB}$ and OD.

\section{DISCUSSION}

This study demonstrated that peer-led education is an effective means in improving the attitudes of junior pharmacy students in the principles of patient safety. Of the four attitudinal domains measured, three domains showed statistically significant improvements as a result of the intervention, with inter-relationships between the domains being highlighted as a result of the use of LGC analysis.

A long-term problem affecting patient safety is healthcare professionals internalise errors rather than addressing them. In this study, students' likelihood to internalise errors was evaluated and it was identified that students who received the intervention had a significant improvement in scores, indicating that they were more likely to address an error rather than internalise or ignore the problem. It is noteworthy that the LGC model contains no statistically significant correlations between the slope of this domain and other measured domains, indicating that changes to this domain only occurred due to the intervention. Hence, educational interventions can facilitate a cultural change from errors being internalised or potentially ignored to that of a culture of where errors are actioned. An associated measure of this concept that has been extensively investigated in the literature is attitudes towards incident reporting. The literature highlights that barriers to reporting centre around the fear of an individual being blamed and shamed. ${ }^{20}$ However, it is shown that interventions can reduce this safety culture issue and improve reporting. ${ }^{21}$ Dudas $e t a l^{22}$ also found that by teaching students to investigate safety issues, their attitudes towards patient safety can be improved, consistent with the results of this study. However, this study is unique as it shows that by training students at the earliest stage of their professional development and by using peers to aid professional socialisation, good practices of addressing an error can be instilled at the earliest stage and potentially become inherent.

Another patient safety area which is of global importance is the open discussion of patient safety issues among healthcare professionals and students, as well as between healthcare professionals and patients. ${ }^{23}$ This study evaluated the effect of the intervention on two related attitudinal domains: questioning behaviours of other healthcare professionals and attitudes towards open disclosure. The LGC model illustrates that changes to students' attitudes towards both of these domains were significantly improved as a result of the intervention. In addition, the model highlights significant correlations between the two attitudinal domains as both attitudes are related to communication skills. As part of the education programme, the peer educators were intentionally used in training the junior students in the communication skills component, including skills taught as part of the TeamSTEPPS training. ${ }^{16} 24$ The use of peer leaders in training students in this area provided students with a more practical approach to learning these skills and in particular, trained students in these techniques using language that junior students would be able to relate to real-world scenarios.

The only domain that did not change as a result of the intervention was students' attitudes towards undertaking quality improvement activities. In this study, we were primarily evaluating the effect of a single 


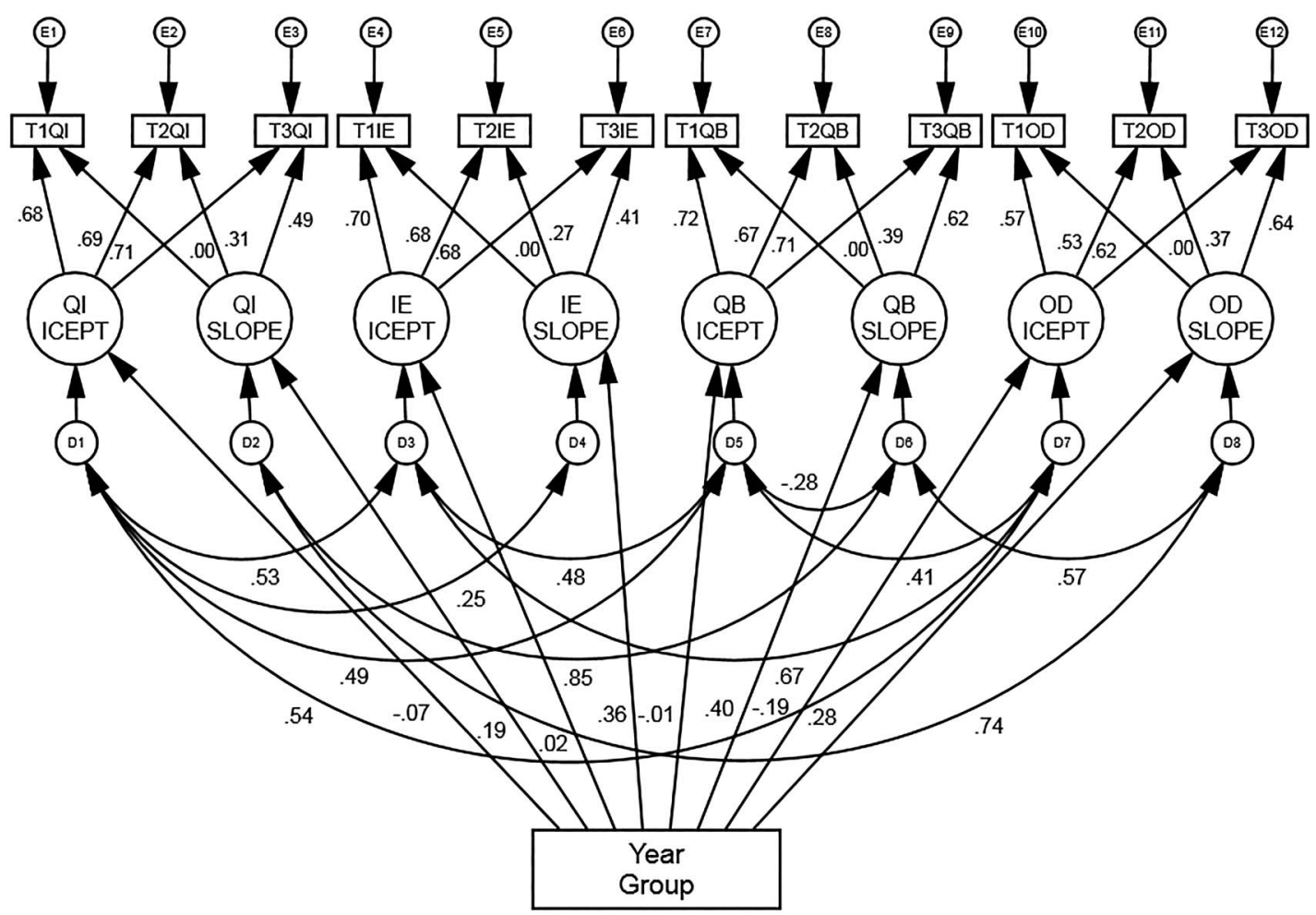

Figure 1 Full latent growth curve (LGC) model evaluating students' attitudes over time.

The diagram consists of the four attitudinal domains being measured: willingness to undertake quality improvement activities (QI); likelihood to internalise errors (IE); likelihood to question behaviours of other healthcare professionals (QB); and willingness to the open disclosure of errors to patients (OD). The growth parameters of intercept (ICEPT) and slope (SLOPE) for each of these domains are illustrated in the diagram. The paths that point from these two parameters point to the respective attitudinal scores measured prior to the intervention (T1), immediately after the intervention (T2) and 1 month after intervention (T3). The year group in which students were enrolled (Year Group) was included in the model as a time invariant predictor of change with first-year students representing the intervention group and second-year students representing the comparator group. Residuals related to the measured attitudinal domains (E1-12) and the growth parameters of intercept and slope (D1-8) are also included in the model.

intervention in affecting students' patient safety attitudes at the start of their degree programmes. At this stage, students have limited clinical experience and responsibility, with much of the placement programme in junior years focusing on socialisation into pharmacy practice. ${ }^{25}$ During this stage of professional infancy, students are likely to be more idealistic than their more senior peers and unable to contextualise some of the complexities of professional practice. ${ }^{26}$ Similarly, other studies of more senior pharmacy students have shown that a short education intervention has a limited effect on attitudes towards implementing quality improvement activities. ${ }^{27}$ Instead, the amount of time spent on education and being involved in quality improvement activities was identified to have a greater impact on students being more quality improvement focused. ${ }^{28}$ It would,

Table 2 Effect of the intervention on students' attitudinal scores ${ }^{*}$

\begin{tabular}{|c|c|c|c|c|c|}
\hline \multicolumn{2}{|c|}{ Attitudinal factor } & \multirow{2}{*}{$\begin{array}{l}\begin{array}{l}\text { Baseline score } \\
\text { (intercept) }\end{array} \\
-0.092\end{array}$} & \multirow{2}{*}{$\begin{array}{l}\begin{array}{l}\text { Baseline } \\
\text { p value }\end{array} \\
0.402\end{array}$} & \multirow{2}{*}{$\begin{array}{l}\begin{array}{l}\text { Rate of changet } \\
\text { (slope) }\end{array} \\
0.059\end{array}$} & \multirow{2}{*}{$\begin{array}{r}\begin{array}{r}\text { Rate of } \\
\text { change } \\
\text { p value }\end{array} \\
0.117\end{array}$} \\
\hline Q। & $\begin{array}{l}\text { Willingness to undertake quality } \\
\text { improvement activities }\end{array}$ & & & & \\
\hline IE & Likelihood to internalise errors & 0.029 & 0.821 & 0.116 & 0.010 \\
\hline QB & $\begin{array}{l}\text { Likelihood to question behaviours of other } \\
\text { healthcare professionals }\end{array}$ & -0.014 & 0.879 & 0.133 & $<0.001$ \\
\hline OD & $\begin{array}{l}\text { Willingness to the open disclosure errors to } \\
\text { patients }\end{array}$ & -0.178 & 0.045 & 0.089 & 0.008 \\
\hline
\end{tabular}


therefore, be beneficial for future work to monitor scores to items in this attitudinal domain as students continue their degree programme and intern year (after completion of their degree programme and prior to registration as a pharmacist) to evaluate how increasing levels of clinical exposure and responsibility will affect this domain.

Overall, this study has demonstrated that by using senior students as educators to junior students in patient safety, effective and positive changes to students' attitudes can be achieved. While studies demonstrate that the use of peer education models may not be superior in teaching students theoretical material such as physiology or pharmacology, studies have demonstrated that peer-led models of education are beneficial in training students and practitioners in clinical and practice-based areas like patient safety. ${ }^{15}{ }^{29}$ Through the use of this model of education, senior students have become positive professional practice role models, which has been shown to influence students positively within the formal, informal and hidden curricula. ${ }^{30} 31$ Consequently, the net effect is that students will strive to practice in a similar manner of their senior peers, encouraging professional socialisation at an earlier stage in their education. ${ }^{9} 32$

In addition to evaluating peer education in changing these attitudinal items, this study has shown that it is possible to train first-year students in patient safety contrary to their lack of professional socialisation. It has been acknowledged in patient safety literature that early commencement of safe practice training is crucial for change. ${ }^{33}$ Henderson et $a l^{7}$ stipulated that having students enter clinical practice with the same safe practice skills as more senior healthcare professionals will ultimately save lives, and hypothesised that a $15-30 \%$ change in attitudes will result in a cultural shift. Studies have shown that students and healthcare professionals at different levels all have differing needs to develop professional practice skills. ${ }^{34}$ Peer education provides a less hierarchical structure in training students in patient safety, allowing greater student interaction and discussion. This ultimately overcomes many of the barriers faced in educating junior students in patient safety principles. In addition, it may also have the benefit of breaking down students' perceptions of the hierarchical structure of clinical practice, which overall can improve safety culture.

\section{Strengths and limitations}

This evaluation study had a number of strengths. First, this study utilised a survey tool that had been previously validated to measure patient safety attitudes of junior pharmacy students. In addition, the large sample size of complete data that was obtained allowed for LGC analysis to be performed. Compared with more traditional analytical methods which only examine variation in mean scores (such as analysis of covariance), LGC analysis is a robust statistical method that enables not only interindividual evaluation but also intraindividual evaluation and allows for correlations to be accounted for in the analysis. ${ }^{35}$ However, despite these strengths, there are also several limitations to the study. First, in order to evaluate the full effect of peer-led education, this study would contain three groups of students: an intervention group that received peer-led education, an intervention group that received more traditional education and a control group. However, to be able to undertake a study with three groups, a much larger sample of first-year students would be required to be able to appropriately evaluate the differences between groups. Furthermore, a study design of this type is unlikely to receive human research ethics approval as students not receiving traditional forms of education may be considered to be disadvantaged. An increased number of survey time points would have enabled a more detailed evaluation of the changes in student attitudes over time; however, to minimise student survey fatigue, it was decided that three time points would be sufficient. Finally, the use of repeated surveys as the tool to evaluate the intervention may limit the magnitude of the effect due to surveys not being able to measure real practice. Despite this fact, it would not be feasible to measure actual practice with first-year students due to the relative lack of clinical training. It is, however, encouraging to see that students' attitudes have improved across a number of areas as a result of the intervention. Future studies would benefit by further evaluating the change in attitudes over the duration of the degree programmes and examining students' safety behaviours during clinical experiential learning placements.

\section{CONCLUSION}

Overall, this study has demonstrated that peer-led education is an effective strategy in training junior-level pharmacy students in basic patient safety principles and also improving attitudes towards patient safety. Furthermore, the study has also found that a number of students' patient safety attitudes are inter-related and that interventions from an early stage of their education can have a significant improvement on their attitudes towards several patient safety domains. Finally, the study has highlighted the importance of educating students about appropriate error management from an early stage, as it is not only crucial in preventing errors from occurring, but also furthering professional socialisation and generational change in the management of errors. Thus, peer-led education has the potential to be a beneficial method in the training of other junior allied healthcare students in patient safety.

Acknowledgements The authors would like to thank Associate Professor Lorraine Smith for assistance in the programme's development and implementation, Dr Stephen Carter for guidance with multivariate analysis, the Faculty of Pharmacy for supporting this project and the undergraduate students who participated in this study. 
Contributors RLW conceived and designed the study, delivered peer leader training, collected and analysed the data and drafted the manuscript. RAF assisted in developing the study, delivered lecture material and peer leader training and revised the manuscript. AJM and TFC assisted in the design of the study and revised the manuscript.

Funding This study was partly funded by the International Pharmaceutical Federation's (FIP) Young Pharmacist/Pharmaceutical Scientist Grant for Professional Innovation 2012.

Competing interests None declared.

Ethics approval Ethical approval to conduct this study was granted by the Human Research Ethics Committee at The University of Sydney (Project Number: 2013/219).

Provenance and peer review Not commissioned; externally peer reviewed.

Data sharing statement No additional data are available.

Open Access This is an Open Access article distributed in accordance with the Creative Commons Attribution Non Commercial (CC BY-NC 4.0) license, which permits others to distribute, remix, adapt, build upon this work noncommercially, and license their derivative works on different terms, provided the original work is properly cited and the use is non-commercial. See: http:// creativecommons.org/licenses/by-nc/4.0/

\section{REFERENCES}

1. Teigland CL, Blasiak RC, Wilson LA, et al. Patient safety and quality improvement education: a cross-sectional study of medical students' preferences and attitudes. BMC Med Educ 2013;13:16.

2. Halbach JL, Sullivan LL. Teaching medical students about medical errors and patient safety: evaluation of a required curriculum. Acad Med 2005;80:600-6.

3. World Health Organization. WHO patient safety curriculum: multi-professional edition. Geneva, Switzerland: WHO Press, 2011.

4. Sandars J, Bax N, Mayer D, et al. Educating undergraduate medical students about patient safety: priority areas for curriculum development. Med Teach 2007;29:60-1.

5. Madigosky WS, Headrick LA, Nelson K, et al. Changing and sustaining medical students' knowledge, skills, and attitudes about patient safety and medical fallibility. Acad Med 2006;81:94-101.

6. Lalor DJ, Chen TF, Walpola R, et al. An exploration of Australian hospital pharmacists' attitudes to patient safety. Int J Pharm Pract 2015;23:67-76.

7. Henderson D, Carson-Stevens A, Bohnen J, et al. Check a box. Save a life: how student leadership is shaking up health care and driving a revolution in patient safety. J Patient Saf 2010;6:43-7.

8. Nimmo CM, Holland RW. Transitions in pharmacy practice, part 4: Can a leopard change its spots? Am J Health Syst Pharm 1999;56:2458-62.

9. Ajjawi R, Higgs J. Learning to reason: a journey of professional socialisation. Adv Health Sci Educ Theory Pract 2008;13:133-50.

10. Smith L, Krass I, Sainsbury E, et al. Pharmacy students' approaches to learning in undergraduate and graduate entry programs. $A m \mathrm{~J}$ Pharm Educ 2010;74:106.

11. Warholak TL, Holdford DA, West D, et al. Perspectives on educating pharmacy students about the science of safety. Am J Pharm Educ 2011;75:142.

12. Aggarwal R, Mytton OT, Derbrew M, et al. Training and simulation for patient safety. Qual Saf Health Care 2010;19(Suppl 2):i34-43.
13. Ahmed M, Arora S, Baker $\mathrm{P}$, et al. Building capacity and capability for patient safety education: a train-the-trainers programme for senio doctors. BMJ Qual Saf 2013;22:618-25.

14. Rubak S, Mortensen L, Ringsted C, et al. A controlled study of the short- and long-term effects of a Train the Trainers course. Med Educ 2008;42:693-702.

15. Secomb J. A systematic review of peer teaching and learning in clinical education. J Clin Nurs 2008;17:703-16.

16. King HB, Battles J, Baker DP, et al. TeamSTEPPS ${ }^{\mathrm{TM}}$ : team strategies and tools to enhance performance and patient safety. Rockville, MD: Agency for Healthcare Research and Quality, 2008.

17. Walpola RL, Fois RA, Carter SR, et al. Validation of a survey tool to assess the patient safety attitudes of pharmacy students. BMJ Open 2015;5:e008442.

18. DiStefano C, Zhu M, Mindrila D. Understanding and using factor scores: considerations for the applied researcher. Pract Assess Res Eval 2009;14:20. http://pareonline.net/getvn.asp? $v=14 \& n=20$

19. Tabachnick BG, Fidell LS. Using multivariate statistics. 6th edn. New Jersey, NJ Pearson, 2013.

20. Waring JJ. Beyond blame: cultural barriers to medical incident reporting. Soc Sci Med 2005;60:1927-35.

21. Evans SM, Smith BJ, Esterman A, et al. Evaluation of an intervention aimed at improving voluntary incident reporting in hospitals. Qual Saf Health Care 2007;16:169-75.

22. Dudas RA, Bundy DG, Miller MR, et al. Can teaching medical students to investigate medication errors change their attitudes towards patient safety? BMJ Qual Saf 2011;20:319-25.

23. O'Connor E, Coates HM, Yardley IE, et al. Disclosure of patient safety incidents: a comprehensive review. Int J Qual Health Care 2010;22:371-9.

24. Brock D, Abu-Rish E, Chiu C-R, et al. Interprofessional education in team communication: working together to improve patient safety. BMJ Qual Saf 2013;22:414-23.

25. Owen S, Stupans I. Australian pharmacy programme experientia placements: comprehensive planning for assessment and evaluation. Assess Eval High Educ 2009;34:579-94.

26. Griffith $\mathrm{CH}$, Wilson JF. The loss of student idealism in the 3rd-year clinical clerkships. Eval Health Prof 2001;24:61-71.

27. Jackson TL. Application of quality assurance principles: teaching medication error reduction skills in a "Real World" environment. Am J Pharm Educ 2004;68:17.

28. Gilligan AM, Myers J, Nash JD, et al. Educating Pharmacy Students to Improve Quality (EPIQ) in colleges and schools of pharmacy. Am $J$ Pharm Educ 2012;76:109.

29. Santee J, Garavalia L. Peer tutoring programs in health professions schools. Am J Pharm Educ 2006;70:70.

30. Cruess SR, Cruess RL, Steinert Y. Role modelling-making the most of a powerful teaching strategy. BMJ 2008;336:718-21.

31. Bradley F, Steven A, Ashcroft DM. The role of hidden curriculum in teaching pharmacy students about patient safety. Am J Pharm Educ 2011;75:143.

32. Howkins EJ, Ewens A. How students experience professional socialisation. Int J Nurs Stud 1999;36:41-9.

33. Kelcíkova S, Skodova Z, Straka S. Effectiveness of hand hygiene education in a basic nursing school curricula. Public Health Nurs 2012;29:152-9.

34. Duggan JM, Hensley S, Khuder S, et al. Inverse correlation between level of professional education and rate of handwashing compliance in a teaching hospital. Infect Control Hosp Epidemiol 2008;29: 534-8.

35. Wimmers PF, Lee M. Identifying longitudinal growth trajectories of learning domains in problem-based learning: a latent growth curve modeling approach using SEM. Adv Health Sci Educ Theory Pract 2015;20:467-78. 